\title{
Future Research: Global Implications
}

\author{
Francine Shapiro ${ }^{\dagger}$ \\ EMDR Institute, Watsonville, California
}

\begin{abstract}
Therapists trained to provide eye movement desensitization and reprocessing (EMDR) therapy have a global responsibility. This article summarizes the multiple impacts of high stress events, and their longterm effects on individuals, families, communities, and nations. While it is well documented that EMDR treatment will remediate the individual symptoms of posttraumatic stress, research is still needed to determine how far-reaching such outcomes are. Future studies should determine whether treatment reverses the neurobiological changes, cognitive deficits, and affective dysregulation, which are associated with exposure to traumatic events. Research should also investigate whether successful treatment decreases high-risk and/or perpetrator behavior, and whether these effects are translated into behavioral and attitudinal changes sufficient to bring an end to intergenerational trauma and ethnopolitical conflicts. It seems self-evident that the ideal way to address pressing societal needs, on both local and global levels, is by the integration of science and practice. The article also discusses the development of nonprofit EMDR humanitarian assistance programs, and their essential work in the alleviation of suffering around the world. In addition to recommending the examination of EMDR's efficacy in treating traumatization from direct, natural, structural, and cultural causes, this article advocates that research resources be dedicated for testing interventions in the areas of the world with the greatest needs. The alleviation of suffering is the duty of our profession.
\end{abstract}

Keywords: eye movement desensitization and reprocessing (EMDR) therapy; research; review; traumatic stress; conflict; suffering

I $\mathrm{n}$ the last two decades, there has been a significant increase in trauma treatment research. This is a welcome development when one considers the wide range of suffering currently experienced worldwide. With the sobering thought in mind, it is advocated here that the field of scientific clinical psychology make an even greater effort to test therapeutic methods that can be implemented in those parts of the world that are in greatest need. Research should be implemented in all of the clinical and societal domains described in this section to evaluate the potential for both remediation prevention through timely treatment.

†Died June 16, 2019

\section{Global Responsibility}

The occurrence of profound psychological disturbance as the outcome of high stress (e.g., rape, combat, natural disaster) is well documented (e.g., Charlson et al., 2016; Fink \& Galea, 2015; McLaughlin et al., 2013; Scott et al., 2014). Such disturbances in turn can lead to a cascade of deleterious effects. For example, it is generally recognized that people who have been exposed to high-stress events are likely to exhibit a variety of physical symptoms (e.g., unexplained illnesses) that may require extended hospital stays and result in increased medical costs and work absences (Afari et al., 2014; Boscarino, 2011; Boscarino, Forsberg, \& Goldberg, 2010; Eslick, Koloski, \& Talley, 2011; McFarlane, 2010; Millegan et al., 2015; Subica, Claypoole, \& Wiley, 2012; Tursich et al., 2014). 
Sometimes the root of the problem is not a specific and dramatic event; rather, it is the accumulation of stressors such as those generally experienced, directly or indirectly, in the inner cities, developing nations, and/or war-torn countries (Anakwenze \& Zuberi, 2013; Bunting, Ferry, Murphy, O’Neill, \& Bolton, 2013: Donley et al., 2012; Miller $\&$ Rasmussen, 2010; Van der Kolk, McFarlane, \& Weisaeth, 1996). Stressors, whether specific or accumulated, can also impair the individual's sense of well-being, and her level of job performance (Barrett, Green, Morris, Giles \& Croft, 1996; Bremner et al., 1993; McFarlane, 2010; Scott et al., 2015; Wrocklage et al., 2016; Van der Kolk, 2014). Also of serious concern are the findings that, if left untreated, trauma and associated stress conditions can impair the physical and mental development of children and contribute to a generational cycle of violence as psychological disturbance (Allen, Hauser, \& Borman-Spurrell, 1996; Bücker et al., 2012; Carr, Martins, Stingel, Lemgruber, \& Juruena, 2013; D’Andrea, Ford, Stolbach, Spinazzola, \& Van der Kolk, 2012; Elklit, Karstoft, Armour, Feddern, \& Christoffersen, 2013; Ellason, Ross, Sainton, \& Lawrence, 1996; Ford et al., 2013; Levenson \& Grady, 2016; Perry, 1997; Perry, Pollard, Blakley, Baker, \& Vigilante, 1995; Read, Fosse, Moskowitz, \& Perry, 2014; Sansone, Lam, \& Wiederman, 2013).

There can be no doubt that many citizens of developing countries are seriously handicapped by the psychological and physical problems directly associated with stress reactions. Although the most obvious effects of exposure to traumatic events include the intrusive thoughts and exaggerated startle responses characterized posttraumatic stress disorder (PTSD), other consequences are not so easily recognized, including mood volatility (e.g., hostile, passive, or depressed reactions), which, if left untreated, can lead to substance abuse, somatic illnesses, and accelerated aging (Bennett \& Kerig, 2014; Miller \& Sadeh, 2014; Van der Kolk, 2014; Van der Kolk et al., 1996; Wolf et al., 2016) as well as memory and concentration problems that can seriously disrupt job and academic performance (Adler et al., 2011; Kira, Lewandoski, Somers, Yoon, \& Chiodo, 2012; Millegan et al., 2015; Perfect, Turley, Carlson, Yohanna, \& Saint Gilles, 2016; Scott et al., 2015; Wrocklage et al., 2016).

Whether individuals are suffering from traumata engendered in developing countries or within the inner cities of developed nations, there is evidence that violence begets violence, and that some of our most prevalent social problems are correlated with trauma histories (Brignone et al., 2016; Donley et al., 2012;
Follette, Polusny, Bechtle, \& Naugle, 1996; Ford, Chapman, Connor, \& Cruise, 2012; Levenson \& Grady, 2016; Stimmel, Cruise, Ford, \& Weiss, 2014; Weiss, Dixon-Gordon, Duke, \& Sullivan, 2015).

Specific research is needed to explore the degree to which successful treatment of trauma decreases the amount of high-risk and/or perpetrator behavior and deters further victimization. Additional research is also needed to explore the degree to which neurobiological changes correlated with traumatization, cognitive deficits, affective dysregulation, and perpetrator behavior (Erickson, Hurley, \& Taber, 2014; Perry, 1997; Perry et al., 1995; Schore, 2001; Siegel, 2012) can be reversed with the judicious application of eye movement desensitization and reprocessing (EMDR), or any other treatment (Barsaglini, Sartori, Benetti, Pettersson-Yeo, \& Mechelli, 2014; Quidé, Witteveen, El-Hage, Veltman, \& Olff, 2012; Schore, Siegel, Shapiro, \& Van der Kolk, 1998; Thomaes et al., 2014). It seems self-evident that the ideal way to address pressing societal needs, on both local and global levels, is by the integration of science and practice.

A final area of proposed future research with important global implications is the examination of the efficacy of EMDR in treating traumatization from direct, natural, structural, and cultural causes (e.g., Carriere, 2014). Untreated traumas can have profound interpersonal and intergenerational consequences, as clearly indicated by research reporting that mothers suffering from PTSD have an increased likelihood of mistreating their children (Chemtob, Gudiño, \& Laraque, 2013). Similarly, Afifi et al. (2012) reported, "Harsh physical punishment [i.e., pushing, grabbing, shoving, slapping, hitting] in the absence of [more severe] child maltreatment is associated with mood disorders, anxiety disorders, substance abuse/dependency, and personality disorders in a general population sample" (p. 184). These findings clearly indicate the need to make effective trauma treatments available worldwide.

Internationally, it is vital to devote resources to the investigation of treatment options with individuals living in underdeveloped areas in the world in which mental health professionals and facilities are scarce. Research should be designed to determine which protocols and procedures can be safely provided by paraprofessionals as psychological first aid. Also of concern in these regions is determining the best ways to remove the stigma about mental health treatment, so that it will be accepted in the same way that offers of physical treatment are embraced. This research has potentially important consequences for peaceful 
coexistence, as attempts at reconciliation of people beset by ethnopolitical violence are often hampered by unprocessed memories of trauma. Research has identified a negative attentional bias in people with PTSD (Pineles, Shipherd, Mostoufi, Abramovitz, \& Yovel, 2009) that hampers their ability to disengage from threatening cues. Clearly, this can have a detrimental effect when attempting to forge agreement and understanding, since the very sight of individuals long viewed as the enemy can disrupt any attempt at reconciliation. Fortunately, preliminary research indicates that EMDR therapy can restore normal cognitive processing and eliminate the attentional bias (El Khoury-Malhame et al., 2011). More research is needed, however, and this should include a direct examination of the effects of EMDR on the process of mediation and reconciliation, as well as attempts to counter the effects of negative historical memories handed down from adults to children that maintain and reinforce cultural antagonisms (e.g., Bombay, Matheson, \& Anisman, 2014). The outcomes of such research will have important implications for reallocating resources and influencing both national and international social policies.

Nonprofit EMDR therapy associations that exist in North and South America, Europe, the Mideast, and Asia set training standards and provide research resources internationally (see Appendix F, Shapiro, 2018). In addition, the nonprofit EMDR humanitarian assistance programs (also listed in Appendix F) offer pro bono training worldwide after natural and manmade disasters to teach local clinicians how to administer EMDR therapy to those in need. These pro bono humanitarian efforts were initiated in response to the Oklahoma city bombing in 1995. An FBI agent on site requested assistance to deal with the traumatized populations in the city. A total of 186 EMDR clinicians from around the country volunteered their services to aid in the recovery process by providing direct services and conducting pro bono trainings. The clinical results of this project were consistent with research published in the same year in the Journal of Clinical and Consulting Psychology (Wilson, Becker, Tinker, 1997; Wilson, Tinker, Becker, 1995), which reported an $84 \%$ elimination of PTSD within three sessions. The nonprofit Trauma Recovery/EMDR Humanitarian Assistance Programs was incorporated later that year and has been providing pro bono services after natural and man-made disasters both domestically and internationally ever since (Gelbach, 2014). Trauma Response Networks mobilize after local disasters such as after the September 11, 2011, terrorist attack to provide treatment, with clinical evaluations indicating substantial treatment effects and a return to normal functioning in the survivors (Silver, Rogers, Knipe, \& Colelli, 2005; see also Alter-Reid, Colelli, \& Simons, 2014). These efforts have been mirrored by national EMDR organizations worldwide (see Shapiro, 2014) that provided pro bono training and treatment after disasters in Africa (Zimmermann, 2014), Asia (Farrell, 2014; Konuk \& Zat, 2015; Mehrotra, 2014), Europe (Fernandez, Callerame, Maslovaric, \& Wheeler, 2014; Mattheß \& Sodermann, 2014), Latin America (Jarero, Artigas, Uribe, \& Miranda, 2014), and the Middle East (Zaghrout-Hodali, 2014). Participating clinicians throughout the world have extended their help, regardless of boundaries and borders, to assist in the alleviation of suffering. It is hoped that through such elimination of suffering we can also help to eliminate the cycle of violence worldwide.

As a helping profession, we must take help to where it is most needed. As a global network of committed clinicians and researchers, we must integrate our therapeutic practices and our scientific rigor in the service of humanity. To this end, the knowledge and practices of all the therapeutic disciplines are needed. I hope that the message of this book has been clear throughout: Clinicians must utilize everything they have ever learned to best serve their clients. EMDR therapy is offered as a tool in that integration process. Likewise, an integration of science and practice is needed to best guide us. The standards of scrutiny can be should be high, rigorous, and appropriate to the real-world concerns of clinicians. The clinicians are those who directly help to alleviate the worlds' suffering. The alleviation of that suffering is the duty of our profession.

\section{Summary and Conclusions}

The clinical effects of EMDR therapy in the treatment of trauma have been demonstrated in numerous randomized controlled trials (RCTs), and EMDR therapy is now considered an empirically validated frontline treatment for PTSD in international guidelines. Research has also demonstrated positive effects with a wide range of other disorders, and additional rigorous RCTs are needed to strengthen and expand this effort. Several theories have been proposed to explain EMDR's therapeutic effects. These theories involve the procedure elements, as well as specific hypotheses about the bilateral stimulation component. The dominant theories involving the therapeutic effect of the eye movements that have received research support include working memory, the orienting response, rapid eye movement (REM) sleep processes, and the 
activation of cortical functions that induce integrative processing.

Much more scientific investigation must be conducted on all of our psychotherapeutic approaches, and issues such as treatment fidelity, the use of appropriate standardized psychometrics and treatment comparisons, and the identification of suitable populations must be directly addressed in order to test methods sufficiently and inform research reviews so as to adequately guide the practicing clinician. Rigorous evaluation must assess both new applications and proposed alterations to the published protocols and procedures.

This book (Shapiro, 2018Shapiro, 2018) has been written to supplement supervised practice conducted by trained experienced EMDR therapy instructors. Whether EMDR education takes place in formal, dedicated training sessions, within mental health agencies, or as part of graduate school curricula, it is only the beginning of the learning process. Once formal training is complete, it becomes the responsibility of all therapists and researchers using EMDR therapy, or any other treatment approach, to continue to upgrade their skills through ongoing practice, supervision, and consultation with more experienced practitioners. EMDR therapy has already help to relieve suffering for millions of people and has affected many more through their association with friends and family. Nevertheless, there are millions more who are suffering worldwide. Consider reaching out to participate in the humanitarian efforts. Seeing life and happiness return to those in need is its own reward. We join together in a commitment to do our best to ensure that no one is left behind.

\section{Note}

The material in this article is a reproduction of pages 422-427, from Francine Shapiro's 2018 text. Reproduced with permission from Francine Shapiro and Guilford Press.

\section{References}

Adler, D. A., Possemato, K., Mavandadi, S., Lerner, D., Chang, H., \& Klaus, J. (2011). Psychiatric status and work performance of veterans of operations enduring freedom and Iraqi freedom. Psychiatric Services, 62(1), 39-46.

Afari, N., Ahumada, S. M., Wright, L. J., Mostoufi, S., Golnari, G., \& Reis, V. (2014). Psychological trauma and functional somatic syndromes: A systematic review and meta-analysis. Psychosomatic Medicine, 76(1), 2-11.
doi:10.1097/PSY.0000000000000010. Epub 2013 Dec 12. Review

Afifi, T. O., Mota, N. P., Dasiewicz, P., MacMillan, H. L., \& Sareen, J. (2012). Physical punishment and mental disorders: Results from a nationally representative US sample. Pediatrics, 30(2), 184-192. doi:10.1542/peds.2011-2947

Allen, J., Hauser, S., \& Borman-Spurrell, E. (1996). Attachment theory as a framework for understanding sequelae of severe adolescent psychopathology: An 11-year follow-up study. Journal of Consulting and Clinical Psychology, 64, 254-263. doi:10.1037 / / 0022-006x.64.2.254

Alter-Reid, K., Colelli, G., \& Simons, N. (2014). When disaster strikes our local communities: U.S. EMDR trauma recovery network coordinators reflect on lessons learned. Journal of EMDR Practice and Research, 8(4), 205214. doi:10.1891/1933-3196.8.4.205

Anakwenze, U., \& Zuberi, D. (2013). Mental health and poverty in the inner city. Health \& Social Work, 38(3), 147-157. doi:10.1093/hsw/hlt013

Barrett, D. H., Green, M. L., Morris, R., Giles, W. H., \& Croft, J. B. (1996). Cognitive functioning and posttraumatic stress disorder. The American Journal of Psychiatry, 153(11), 1492-1494. doi:10.1176/ajp.153.11.1492

Barsaglini, A., Sartori, G., Benetti, S., Pettersson-Yeo, W., \& Mechelli, A. (2014). The effects of psychotherapy on brain function: A systematic and critical review. Progress in Neurobiology, 114, 1-14. doi:10.1016/j. pneurobio.2013.10.006

Bennett, D. C., \& Kerig, P. K. (2014). Investigating the construct of trauma-related acquired callousness among delinquent youth: Differences in emotion processing. Journal of Traumatic Stress, 27(4), 415-422. doi: $10.1002 /$ jts. 21931

Bombay, A., Matheson, K., \& Anisman, H. (2014). The intergenerational effects of Indian residential schools: Implications for the concept of historical trauma. Transcultural Psychiatry, 51(3), 320-338. doi:10.1177/ 1363461513503380

Boscarino, J. A. (2011). Post-traumatic stress disorder and cardiovascular disease link: Time to identify specific pathways and interventions. American Journal of Cardiology, 108(7), 1052-1053. doi:10.1016/j.amjcard. 2011.07.003

Boscarino, J. A., Forsberg, C. W., \& Goldberg, J. (2010). A twin study of the association between PTSD symptoms and rheumatoid arthritis. Psychosomatic Medicine, 72(5), 481-486. doi:10.1097/ PSY.0b013e3181d9a80c

Bremner, J., Scott, T., Delaney, R., Southwick, S., Mason, J., Johnson, D., . . . Charney, D. (1993). Deficits in short-term memory in posttraumatic stress disorder. American Journal of Psychiatry, 150, 1015-1019. doi:10.1176/ajp.150.7.1015

Brignone, E., Gundlapalli, A. V., Blais, R. K., Carter, M. E., Suo, Y., \& Samore, M. H. (2016). Differential risk for homelessness among us male and female veterans with a positive screen for military sexual 
trauma. JAMA Psychiatry, 73(6), 582-589. doi:10.1001/ jamapsychiatry.2016.0101

Bücker, J., Kapczinski, F., Post, R., Ceresér, K. M., Szobot, C., \& Yatham, L. N. (2012). Cognitive impairment in school-aged children with early trauma. Comprehensive Psychiatry, 53(6), 758-764. doi:10.1016/j. comppsych.2011.12.006

Bunting, B. P., Ferry, F. R., Murphy, S. D., O’Neill, S. M., \& Bolton, D. (2013). Trauma associated with civil conflict and posttraumatic stress disorder: Evidence from the Northern Ireland study of health and stress. Journal of Traumatic Stress, 26(1), 134-141. doi:10.1002/jts.21766

Carr, C. P., Martins, C. M., Stingel, A. M., Lemgruber, V. B., \& Juruena, M. F. (2013). The role of early life stress in adult psychiatric disorders: A systematic review according to childhood trauma subtypes. Journal of Nervous and Mental Disease, 201(12), 1007-1020. doi:10.1097/ NMD.0000000000000049

Carriere, R. C. (2014). Scaling up what works: Using EMDR to help confront the world's burden of traumatic stress. Journal of EMDR Practice and Research, 8(4), 187-195. doi:10.1891/1933-3196.8.4.187

Charlson, F. J., Flaxman, A., Ferrari, A. J., Vos, T., Steel, Z., \& Whiteford, H. A. (2016). Post-traumatic stress disorder and major depression in conflict-affected populations: An epidemiological model and predictor analysis. Global Mental Health, 3, e4. doi:10.1017 / gmh.2015.26

Chemtob, C. M., Gudiño, O. G., \& Laraque, D. (2013). Maternal posttraumatic stress disorder and depression in pediatric primary care: Association with child maltreatment and frequency of child exposure to traumatic events. JAMA Pediatrics, 167(11), 1011-1018. doi:10.1001/jamapediatrics.2013.2218

D’Andrea, W., Ford, J., Stolbach, B., Spinazzola, J., \& Van der Kolk, B. A. (2012). Understanding interpersonal trauma in children: Why we need a developmentally appropriate trauma diagnosis. American Journal of Orthopsychiatry, 82(2), 187-200. doi:10.1111/j.19390025.2012.01154.x

Donley, S., Habib, L., Jovanovic, T., Kamkwalala, A., Evces, M., \& Egan, G. (2012). Civilian PTSD symptoms and risk for involvement in the criminal justice system. Journal of American Academy of Psychiatry and Law Online, 40(4), 522-529.

El Khoury-Malhame, M., Lanteaume, L., Beetz, E. M., Roques, J., Reynaud, E., \& Samuelian, J. C. (2011). Attentional bias in post-traumatic stress disorder diminishes after symptom amelioration. Behavior Research and Therapy, 49(11), 796-801. doi:10.1016/j.brat.2011.08.006

Elklit, A., Karstoft, K. I., Armour, C., Feddern, D., \& Christoffersen, M. (2013). Predicting criminality from child maltreatment typologies and posttraumatic stress symptoms. European Journal of Psychotraumatology, 4, Article 19825. doi:10.3402/ ejpt.v4i0.19825

Ellason, J., Ross, C., Sainton, K., \& Lawrence, W. (1996). Axis I and II comorbidity and childhood trauma history in chemical dependency. Bulletin of the Menninger Clinic, 60, 39-51.

Erickson, H. J., Hurley, R. A., \& Taber, K. (2014). Psychotherapy for PTSD: Neuroimaging of recovery processes. Journal of Neuropsychiatry and Clinical Neurosciences, 26(3), 188-195. doi:10.1176/appi.neuropsych.260301

Eslick, G. D., Koloski, N. A., \& Talley, N. J. (2011). Sexual, physical, verbal/emotional abuse and unexplained chest pain. Child Abuse and Neglect, 35(8), 601-605. doi:10.1016/j.chiabu.2011.04.007

Farrell, D. (2014). Developing EMDR therapy in Pakistan as part of a humanitarian endeavor. Journal of EMDR Practice and Research, 8(4), 233-239. doi:10.1891/19333196.8.4.233

Fernandez, I., Callerame, C., Maslovaric, G., \& Wheeler, K. (2014). EMDR Europe humanitarian programs: Development, current status, and future challenges. Journal of EMDR Practice and Research, 8(4), 215-224. doi:10.1891/1933-3196.8.4.181

Fink, D. S., \& Galea, S. (2015). Life course epidemiology of trauma and related psychopathology in civilian populations. Current Psychiatry Reports, 17(5), 31. doi:10.1007/s11920-015-0566-0

Follette, V. M., Polusny, M. A., Bechtle, A. E., \& Naugle, A. E. (1996). Cumulative trauma: The impact of child sexual abuse, adult sexual assault, and spouse abuse. Journal of Traumatic Stress, 9, 25-35.

Ford, J. D., Chapman, J., Connor, D. F., \& Cruise, K. R. (2012). Complex trauma and aggression in secure juvenile justice settings. Criminal Justice and Behavior, 39(6), 694-724. doi:10.1177/0093854812436957

Ford, J. D., Grasso, D., Greene, C., Levine, J., Spinazzola, J., \& van der Kolk, B. (2013). Clinical significance of a proposed developmental trauma disorder diagnosis: Results of an international survey of clinicians. Journal of Clinical Psychiatry, 74(8), 841-849. doi:10.4088/JCP.12m08030

Gelbach, R.(2014). EMDR humanitarian assistance programs: 20 years and counting. Journal of EMDR Practice and Research, 8(4), 196-204. doi:10.1891/19333196.8.4.196

Jarero, I., Artigas, L., Uribe, S., \& Miranda, A. (2014). EMDR therapy humanitarian trauma recovery interventions in Latin America and the Caribbean. Journal of EMDR Practice and Research, 8(4), 260-268. doi:10.1891/19333196.8.4.260

Kira, I., Lewandowski, L., Somers, C. L., Yoon, J. S., \& Chiodo, L. (2012, January). The effects of trauma types, cumulative trauma, and PTSD on IQ in two highly traumatized adolescent groups. Psychological Trauma: Theory, Research, Practice, and Policy, 4(1), 128-139.

Konuk, E., \& Zat, Z. (2015). Humanitarian programs and interventions in Turkey. Journal of EMDR Practice and Research, 9(2), 106-113. doi:10.1891/1933-3196.9.2.106

Levenson, J. S., \& Grady, M. D. (2016). The influence of childhood trauma on sexual violence and sexual 
deviance in adulthood. Traumatology, 22(2), 94-103. doi: $10.1037 / \operatorname{trm} 0000067$

Mattheß, H., \& Sodemann, U. (2014). Trauma-aid, humanitarian assistance program Germany. Journal of EMDR Practice and Research, 8(4), 225-232. doi:10.1891/19333196.8.4.225

McFarlane, A. C. (2010). The long-term costs of traumatic stress: Intertwined physical and psychological consequences. World Psychiatry, 9(1), 3-10.

McLaughlin, K. A., Koenen, K. C., Hill, E. D., Petukhova, M., Sampson, N. A., \& Zaslavsky, A. M. (2013). Trauma exposure and posttraumatic stress disorder in a national sample of adolescents. Journal of the American Academy of Child and Adolescent Psychiatry, 52(8), 815-830.e14. doi:10.1016/j.jaac.2013.05.011

Mehrotra, S. (2014). Humanitarian projects and growth of EMDR therapy in Asia. Journal of EMDR Practice and Research, 8(4), 252-259. doi:10.1891/1933-3196.8.4.252

Millegan, J., Milburn, E. K., LeardMann, C. A., Street, A. E., Williams, D., Trone, D. W., \& Crum Cianflone, N. F. (2015). Recent sexual trauma and adverse health and occupational outcomes among U.S. service women. Journal of Traumatic Stress, 28, 298-306. doi: $10.1002 /$ jts. 22028

Miller, K. E., \& Rasmussen, A. (2010). War exposure, daily stressors, and mental health in conflict and post-conflict settings: Bridging the divide between trauma-focused and psychosocial frameworks. Social Science and Medicine, 70(1), 7-16. doi:10.1016/ j.socscimed.2009.09.029

Miller, M. W., \& Sadeh, N. (2014). Traumatic stress, oxidative stress and post-traumatic stress disorder: Neurodegeneration and the accelerated-aging hypothesis. Molecular Psychiatry, 19(11), 1156-1562. doi:10.1038/ mp.2014.111

Perfect, M. M., Turley, M. R., Carlson, J. S., Yohanna, J., \& Saint Gilles, M. P. (2016). School-related outcomes of traumatic event exposure and traumatic stress symptoms in students: A systematic review of research from 1990 to 2015.. School Mental Health, 8(1), 7-43. doi:10.1007/s12310-016-9175-2

Pineles, S. L., Shipherd, J. C., Mostoufi, S. M., Abramovitz, S. M., \& Yovel, I. (2009). Attentional biases in PTSD: More evidence for interference. Behavior Research and Therapy, 47(12), 1050-1057. doi:10.1016/j.brat.2009.08.001

Perry, B. (1997). Incubated in terror: Neurodevelopmental factors in the cycle of violence. In J. Osofsky (Ed.), Children, youth and violence: Searching for solutions (pp. 124149). New York, NY: Guilford.

Perry, B., Pollard, R., Blakley, T., Baker, W., \& Vigilante, D. (1995). Childhood trauma, the neurobiology of adaptation, and "use-dependent" development of the brain: How "states" become "traits.". Infant Mental Health Journal, 16, 271-290. doi:10.1002/1097-0355 (199524)16:4<271::AID-IMHJ2280160404>3.0.CO;2-B
Quidé, Y., Witteveen, A. B., El-Hage, W., Veltman, D. J., \& Olff, M. (2012). Differences between effects of psychological versus pharmacological treatments on functional and morphological brain alterations in anxiety disorders and major depressive disorder: A systematic review. Neuroscience and Biobehavioral Reviews, 36(1), 626644. doi:10.1016/j.neubiorev.2011.09.004

Read, J., Fosse, R., Moskowitz, A., \& Perry, B. (2014). The traumagenic neurodevelopmental model of psychosis revisited. Neuropsychiatry, 4(1), 65-79. doi:10.2217/ NPY.13.89

Sansone, R. A., Lam, C., \& Wiederman, M. W. (2013). Victims of bullying in childhood, criminal outcomes in adulthood. International Journal of Psychiatry in Clinical Practice, 17(1), 69-72. doi:10.3109/13651501.2012.693185

Schore, A. N. (2001). The effects of early relational trauma on right brain development, affect regulation, and infant mental health. Infant Mental Health Journal, 22, 201-269.

Schore, A. N., Siegel, D. J., Shapiro, F., \& Van der Kolk, B. A. (1998, January). Developmental and neurobiological underpinnings of trauma. Plenary panel presented at Understanding and Treating Trauma: Developmental and Neurobiological Approaches Conference, Los Angeles.

Scott, J. C., Matt, G. E., Wrocklage, K. M., Crnich, C., Jordan, J., \& Southwick, S. M. (2015). A quantitative meta-analysis of neurocognitive functioning in posttraumatic stress disorder. Psychological Bulletin, 141(1), 105140. doi:10.1037/a0038039

Scott, J. C., Pietrzak, R. H., Southwick, S. M., Jordan, J., Silliker, N., \& Brandt, C. A. (2014). Military sexual trauma interacts with combat exposure to increase risk for posttraumatic stress symptomatology in female Iraq and Afghanistan veterans. Journal of Clinical Psychiatry, 75(6), 637-643. doi:10.4088/JCP.13m08808

Shapiro, F. (2018). Eye movements desensitization and reprocessing. Basic principles, protocols, and procedures (3rd ed.). New York, NY: Guilford Press.

Shapiro, F. (2014). EMDR therapy humanitarian assistance programs: Treating the psychological, physical, and societal effects of adverse experiences worldwide. Journal of EMDR Practice and Research, 8(4), 181-186. doi:10.1891/1933-3196.8.4.181

Siegel, D. J. (2012). The developing mind: How relationships and the brain interact to shape who we are. New York, NY: Guilford Press.

Silver, S. M., Rogers, S., Knipe, J., \& Colelli, G. (2005). EMDR therapy following the 9/11 terrorist attacks: A community-based intervention project in New York City. International Journal of Stress Management, 12(1), 2942. doi:10.1037/ 1072-5245.12.1.29

Stimmel, M. A., Cruise, K. R., Ford, J. D., \& Weiss, R. A. (2014). Trauma exposure, posttraumatic stress disorder symptomatology, and aggression in male juvenile offenders. Psychological Trauma: Theory, Research, Practice, and Policy, 6(2), 184-191. doi:10.1037/a0032509 
Subica, A. M., Claypoole, K. H., \& Wiley, A. M. (2012). 104-109.PTSD'S mediation of the relationships between trauma, depression, substance abuse, mental health, and physical health in individuals with severe mental illness: Evaluating a comprehensive model. Schizophrenia Research, 136(1-3), 104-109.

Thomaes, K., Dorrepaal, E., Draijer, N., Jansma, E. P., Veltman, D. J., \& Van Balkom, A. J. (2014). Can pharmacological and psychological treatment change brain structure and function in PTSD? A systematic review. Journal of Psychiatric Research, 50, 1-15. doi:10.1016/j.jpsychires.2013.11.002

Tursich, M., Neufeld, R. W. J., Frewen, P. A., Harricharan, S, Kibler, J. L., Rhind, S. G., et al. (2014). Association of trauma exposure with proinflammatory activity: A transdiagnostic meta-analysis. Translational Psychiatry, 4, e413. doi:10.1038/tp.2014.56

Van der Kolk, B. A. (2014). The body keeps the score: Brain, mind, and body in the healing of trauma. New York, NY: Viking.

Van der Kolk, B., McFarlane, A., \& Weisaeth, L. (1996). Traumatic stress: The effects of overwhelming experience on mind, body, and society.. New York, NY: Guilford Press.

Weiss, N. H., Dixon-Gordon, K. L., Duke, A. A., \& Sullivan, T. P. (2015). The underlying role of posttraumatic stress disorder symptoms in the association between intimate partner violence and deliberate self-harm among African American women. Comprehensive Psychiatry, 59, 8-16.

Wilson, S. A., Becker, L. A., \& Tinker, R. H. (1997). Fifteenmonth follow-up of eye movement desensitization and reprocessing (EMDR) treatment for PTSD and psychological trauma. Journal of Consulting and Clinical Psychology, 65, 1047-1056. doi:10.1037/ / 0022-006x.63.6.928
Wilson, S. A., Tinker, R. H., \& Becker, L. A. (1995). Eye movement desensitization and reprocessing (EMDR) treatment for psychologically traumatized individuals. Journal of Consulting and Clinical Psychology, 63, 928-937.

Wolf, E. J., Logue, M. W., Hayes, J. P., Sadeh, N., Schichman, S. A., \& Stone, A. (2016). Accelerated DNA methylation age: Associations with posttraumatic stress disorder and neural integrity. Psychoneuroendocrinology, 63, 155-162. doi:10.1016/j.psyneuen.2015.09.020

Wrocklage, K. M., Schweinsburg, B. C., Krystal, J. H., Trejo, M., Roy, A., \& Weisser, V. (2016). Neuropsychological functioning in veterans with posttraumatic stress disorder: Associations with performance validity, comorbidities, and functional outcomes. Journal of the International Neuropsychological Society, 22(4), 399-411. doi:10.1017/S1355617716000059

Zaghrout-Hodali, M. (2014). Humanitarian work using EMDR in Palestine and the Arab world. Journal of EMDR Practice and Research, 8(4), 248-251. doi:10.1891/19333196.8.4.248

Zimmermann, E. (2014). EMDR humanitarian work: Providing trainings in EMDR therapy to African clinicians. Journal of EMDR Practice and Research, 8(4), 240-247. doi:10.1891/1933-3196.8.4.240

Disclosure. Francine Shapiro was the author of many published books about EMDR therapy and was the founder of the EMDR Institute, which provides EMDR training.

Correspondence regarding this article should be directed to EMDR Institute, Inc., P.O. Box 750, Watsonville, CA 95077. E-mail: inst@emdr.com 